TEKNIK, 40 (1), 2019, 1-10

\title{
Pengembangan Robot Humanoid Pemain Bola Otonom
}

\author{
Hadha Afrisal ${ }^{1 *}$, Munadi ${ }^{2}$, Muhammad Faris ${ }^{3}$, Bakhtiar Alldino A.S. ${ }^{4}$ \\ ${ }^{1}$ Departemen Teknik Elektro, Fakultas Teknik, Universitas Diponegoro, \\ ${ }^{2}$ Departemen Teknik Mesin, Fakultas Teknik, Universitas Diponegoro, \\ Jl. Prof. Soedarto, SH, Kampus UNDIP Tembalang, Semarang, Indonesia 50275 \\ ${ }^{3}$ Departemen Teknik Elektro dan Teknologi Informasi, Fakultas Teknik, Universitas Gadjah Mada, \\ ${ }^{4}$ Departemen Ilmu Komputer dan Elektronika, Fakultas MIPA, Universitas Gadjah Mada, \\ Bulaksumur, Yogyakarta, Indonesia 55281
}

\begin{abstract}
Abstrak
Penelitian ini bertujuan mengembangkan robot humanoid untuk permainan sepakbola secara otomatis. Robot humanoid yang dikembangkan tersusun atas 20 sendi yang digerakkan dengan motor servo dynamixel berjenis AX-12 (bagian tubuh atas) dan RX-24 (bagian tubuh bawah), serta dikontrol menggunakan board servo-controller CM-700 (ATMega2561). Robot humanoid memiliki tinggi $44 \mathrm{~cm}$ serta dilengkapi dengan sistem keseimbangan menggunakan sensor gyro LPR530 dan akselerometer KXM52-1050. Untuk mengenali objek dan bernavigasi secara otomatis, robot humanoid menggunakan sistem sensor visual berbasiskan kamera CMOS dengan board CMUCAM (LPC2106). Pengujian menunjukkan bahwa robot humanoid pemain bola yang dikembangkan mampu berjalan dengan kecepatan rata-rata $14.37 \mathrm{~cm} /$ detik dan memiliki kecepatan maksimal $20 \mathrm{~cm} /$ detik. Robot humanoid yang dikembangkan mampu bermain bola secara otomatis: yakni mampu mendeteksi keberadaan bola, mendeteksi lokasi gawang, serta menendang bola ke arah gawang dan mencetak gol.
\end{abstract}

Kata kunci: robot; humanoid; sepakbola; otonom; deteksi bola

\begin{abstract}
[Title: The Development of Autonomous Humanoid Soccer Robot] This research aims to develop an autonomous humanoid soccer robot. The humanoid soccer robot is designed using 20 joints which are equipped with dynamixel servo motor AX-12 (upper body) and RX-24 (lower body) and is controlled by using servo controller board CM-700 (ATMega2561). The humanoid soccer robot is $44 \mathrm{~cm}$ in height and is equipped with a balancing system of using gyro sensor LPR530 and accelerometer KXM52-1050. In order to detect object and to navigate autonomously, the humanoid soccer robot is equipped with a CMOS camera which is controlled using CMUCAM board (LPC2016). The experiment shows that the humanoid soccer robot has ability to walk with average speed of $14.37 \mathrm{~cm} / \mathrm{second}$ and is able to achieve a top speed of up to $20 \mathrm{~cm} / \mathrm{second}$. The developed humanoid soccer robot can play soccer autonomously: to locate the ball, to detect the goalpost, and to score the goal to the goalpost.
\end{abstract}

Keywords: robot; humanoid; soccer; autonomous; ball detection

\section{Pendahuluan}

Para ilmuwan pengembang robot humanoid melalui organisasi RoboCup bercita-cita untuk mengembangkan robot humanoid yang akan siap untuk bertanding dengan tim sepakbola manusia pada tahun

\footnotetext{
*) Penulis Korespondensi.

E-mail: hadha.afrisal@elektro.undip.ac.id
}

2050 (Gerndt, Seifert, Baltes, Sadeghnejad, \& Behnke, 2015). Sepakbola dipilih sebagai patokan keberhasilan riset robot humanoid karena di dalam permainan sepakbola terdapat aspek-aspek kecerdasan fisik, yakni perpaduan antara ketangkasan motorik yang didukung dengan kecerdasan sensorik. Pemain sepakbola diharuskan memiliki fisik yang kuat dan lincah, serta memiliki kemampuan analisa dan kerjasama yang tinggi. 


\section{TEKNIK, 40 (1), 2019, 2}

Aspek-aspek tersebutlah yang menjadikan sepakbola dipilih sebagai tolok ukur keberhasilan pengembangan robot humanoid. Robot humanoid yang dikembangkan diharapkan memenuhi prasyarat antara lain: memilki struktur mekanik yang kokoh dan ringan, sistem keseimbangan tubuh yang mumpuni, kecepatan dan kelincahan dalam navigasi, serta kecerdasan untuk mengenali objek (Burkhard, et al., 2002).

Robot humanoid pemain bola didesain memiliki tinggi tubuh antara $30 \mathrm{~cm}$ sampai $60 \mathrm{~cm}$ untuk bermain dalam sebuah miniatur lapangan sepakbola berukuran $6 \times 4$ meter. Masing-masing tim yang bertanding terdiri dari 3 buah robot humanoid yang berfungsi sebagai kiper, pemain bertahan, dan pemain serang. Robot bermain bola secara autonomous dengan mengandalkan sensor visual berupa kamera. Untuk memenuhi kualifikasi tersebut, robot humanoid pemain bola yang dikembangkan ini terdiri dari 20 sendi dan dengan tinggi tubuh $44 \mathrm{~cm}$. Masing-masing sendi digerakkan oleh smart servo dynamixel AX-12 dan RX-24 yang memiliki spesifikasi torsi yang cocok untuk pengembangan robot humanoid berukuran kecil (Kim, Son, \& Kim, 2004). Sistem penglihatan robot menggunakan modul kamera C3088 dengan board CMUCAM yang sekaligus berfungsi sebagai main controller pada robot. Untuk mengendalikan pergerakan motor servo pada robot serta membaca nilai gyro dan akselerometer pada sistem keseimbangan dan falldetection, robot menggunakan board CM-700 (ATMega2561).

\section{Bahan dan Metode}

\section{1. Sistem Mekanik, Aktuator dan Keseimbangan}

Sistem Mekanik: Perancangan sistem mekanik robot dilakukan dengan menggunakan software AutoCAD Inventor. Rancangan robot ditampilkan pada Gambar 1 (sebelah kiri) dengan spesifikasi mekanik sebagai berikut,

1. Rangka robot menggunakan bahan aluminium tipe 5 dengan tebal $3 \mathrm{~mm}$, digunakan pada seluruh tubuh robot kecuali pada bagian kepala yang menggunakan aluminium $2 \mathrm{~mm}$.

2. Sendi-sendi yang menggerakkan upper body (bagian tubuh - mencakup tangan dan kepala) menggunakan servo dynamixel seri AX-12.

3. Sendi-sendi pada lower body (bagian kaki) digerakkan oleh servo dynamixel seri RX-24.

4. Baterai dipasang di bagian bawah kaki (sebelah kanan dan kiri secara paralel). Rangkaian kontroler diletakkan pada bagian punggung.

Idealnya, sensor keseimbangan terletak tepat di posisi Center of Mass (CoM) robot saat kondisi standby untuk berjalan. Pada perancangan, sensor keseimbangan yang terdiri dari gyro dan akselerometer yang disusun bertumpuk pada sumbu $\mathrm{Z}$ berada pada posisi $270 \mathrm{~mm}$ dari titik terbawah robot pada saat robot berdiri tegak. Pengukuran CoM robot dilakukan saat bagian-bagian robot sudah terpasang dengan lengkap, termasuk pengkabelan, baterai, dan sebagainya. Postur robot saat berjalan ditunjukkan pada Gambar 1. Posisi kaki robot saat standby diposisikan menekuk guna menyesuaikan agar sensor keseimbangan robot berada mendekati titik CoM. Pada postur standby, CoM robot humanoid terletak pada ketinggian $220 \mathrm{~mm}$. Pemasangan sensor keseimbangan menggunakan sumbu $\mathrm{X}$ dan $\mathrm{Y}$, sedangkan sumbu $\mathrm{Z}$ diabaikan untuk simplifikasi proses kontrol. Guna mengoreksi ayunan gerakan ke depan dan ke belakang, pada robot digunakan input sensor keseimbangan di sumbu X, sedangkan untuk mengoreksi ayunan gerakan ke samping kanan dan kiri digunakan input sensor keseimbangan pada sumbu Y.

Aktuator: Aktuator yang digunakan pada robot humanoid adalah smart servo dynamixel seri AX-12 dan RX-24, dimana kedua jenis servo tersebut memiliki kualitas aktuasi yang cukup presisi dan halus. Dynamixel merupakan smart servo yang didesain khusus untuk digunakan pada robot humanoid. Jika dibandingkan dengan servo-servo lain, dynamixel memiliki keunggulan antara lain adanya fitur feedback untuk mengontrol dan memonitor posisi dan torsi secara akurat. Terlebih lagi dengan desainnya yang modular bertopologi Daisy Chain, dynamixel lebih efisien diterapkan pada robot humanoid (Thai, 2017). Meskpun torsi yang dihasilkan oleh RX-24 lebih besar dibanding dengan AX-12, namun RX-24 lebih boros daya sehingga RX-24 hanya digunakan untuk menopang sendi-sendi yang membutuhkan penggerak dengan torsi lebih besar seperti pada bagian tubuh bawah.

Sistem keseimbangan: Pada robot pemain bola, sistem keseimbangan berbasis inersia sebenarnya hanya dibutuhkan ketika terjadi ketidakseimbangan yang diakibatkan slip, sandungan, atau tabrakan, sehingga pada kondisi normal locomotion robot dapat dianggap sebagai static walking (Mobalegh, 2012). Sistem keseimbangan robot humanoid menggunakan sensor gyro dan akselerometer, dengan pemodelan sistem keseimbangan Cart-Table Model (Kajita, et al., 2003). Pada sistem keseimbangan dan fall-detection, gyro yang digunakan adalah LPR530AL produksi ST yang mampu mendeteksi kecepatan putar 2 axis (pitch dan roll) hingga maksimal $300 \%$ detik. Dengan menggunakan supply tegangan 3 Volt dan tegangan referensi 1.23 Volt, pada masing-masing axis, gyro akan mendeteksi kondisi diam (zero rate level) pada tegangan 1.23 Volt. Saat terjadi kecepatan sudut maksimal (300\% detik) pada arah positif, gyro akan mengeluarkan tegangan 2.23 Volt dan sebaliknya jika terjadi kecepatan sudut maksimal pada arah negatif gyro akan mengeluarkan nilai tegangan 0.23 Volt (Antonello \& Oboe, 2011). 


\section{TEKNIK, 40 (1), 2019, 3}
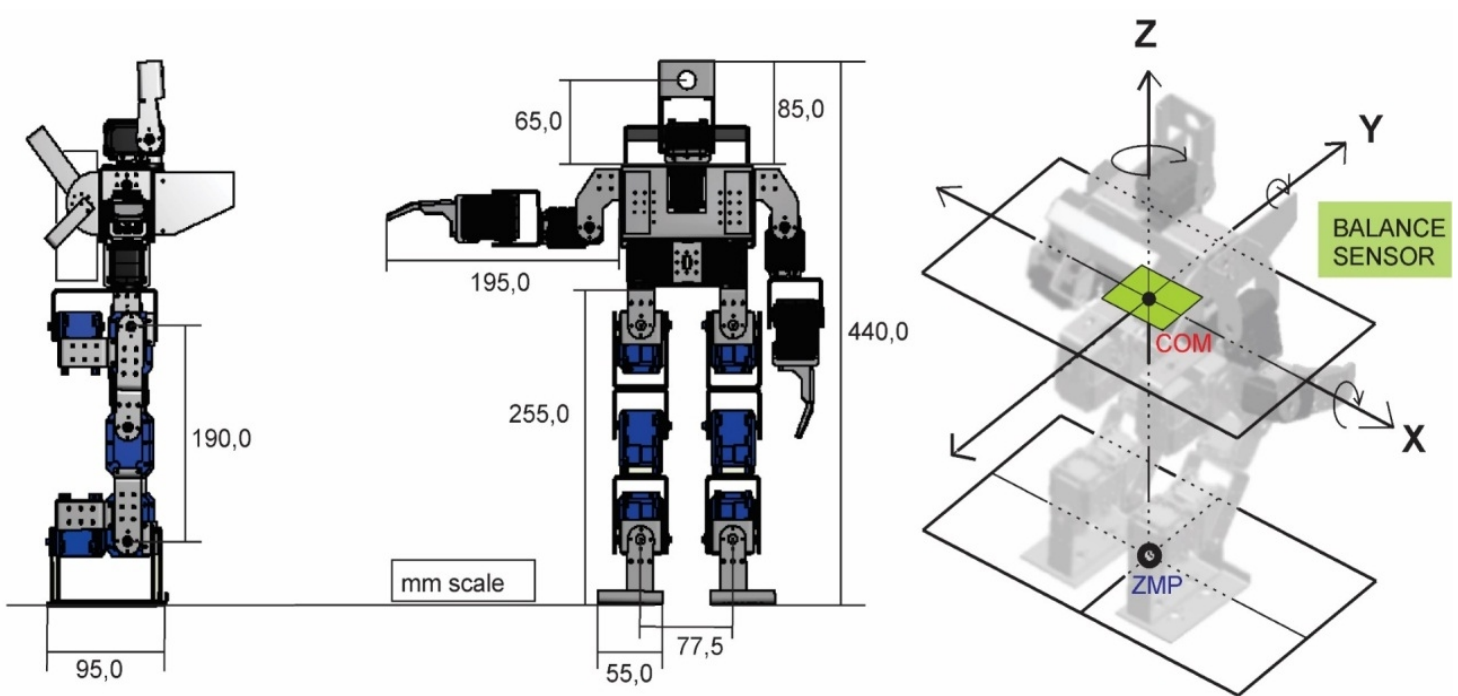

Gambar 1. Rancangan Mekanis Robot Humanoid dan Penempatan Sensor Keseimbangan pada Tubuh Robot Humanoid

Akselerometer merupakan sensor untuk mengukur percepatan, namun sebenarnya yang diukur oleh akselerometer adalah gaya yang didapat per satuan massa (Acceleration $=$ Force $/$ Mass). Saat akselerometer diam atau bergerak dalam kecepatan konstan, keluaran akselerometer tidak bernilai nol melainkan akan mendeteksi percepatan gravitasi pada sumbu yang memiliki komponen yang tegak lurus terhadap permukaan bumi. Akselerometer yang digunakan pada robot humanoid adalah 3-axis KXM521050 produksi Kionix. Akselerometer tersebut dapat mendeteksi percepatan pada 3 sumbu yang saling tegak lurus yaitu sumbu $\mathrm{X}, \mathrm{Y}$, dan $\mathrm{Z}$ dengan masing-masing sumbu mampu mendeteksi percepatan bernilai maksimal \pm 2 g. Output sensor ini berupa tegangan dengan tegangan kerja antara 3 Volt sampai 7 Volt. Keluaran tegangan sensor saat tidak terjadi akselerasi $(0 \mathrm{~g})$ adalah setengah dari sumber tegangan supply. Sensor tersebut memiliki sensitivitas 1 Volt/g (Bliley, et al., 2006).

Ada beberapa sistem pemodelan untuk mengendalikan keseimbangan robot humanoid. Dua jenis pemodelan yang paling terkenal adalah Linear Inverted Pendulum Model (LIPM) dan Cart-Table Model (CTM) (Peng, Shui, Li, \& Ma, 2010). Pada sistem keseimbangan robot humanoid pemain bola, model yang digunakan adalah Cart-Table Model seperti yang dijelaskan oleh Kajita (Kajita, et al., 2003). Selain itu pada robot juga ditambahkan guidance control pada tangan sebagai penyeimbang tetap tegaknya tubuh robot. Pergerakan robot humanoid dirancang sehingga posisi upper body tetap tegak (sama dengan posisi standby) meskipun saat robot sedang melangkahkan kaki. Pemodelan dengan CTM lebih mudah diterapkan pada robot humanoid kecil dengan sistem kontroler yang memiliki kemampuan processing kecil. Namun sebagai konsekuensinya, pergerakan robot menjadi cenderung kaku karena upper body dipertahankan agar tetap tegak. Untuk memperhalus gerakan robot sekaligus sebagai penyeimbang, maka digunakan sistem Hand-Balancing. Gambar 2 menampilkan visualisasi pemodelan keseimbangan humanoid dengan CTM dengan persamaan matematis yang diuraikan pada persamaan (1) dan (2). Model matematis tersebut digunakan untuk mengontrol Zero Moment Point (ZMP) saat robot melangkah, yaitu dengan mengontrol pergeseran ZMP pada sumbu $x$ dan sumbu y. Selanjutnya, nilai selisih pergeseran ZMP tersebut digunakan sebagai faktor pengali pada kompensator di masing-masing motor servo.

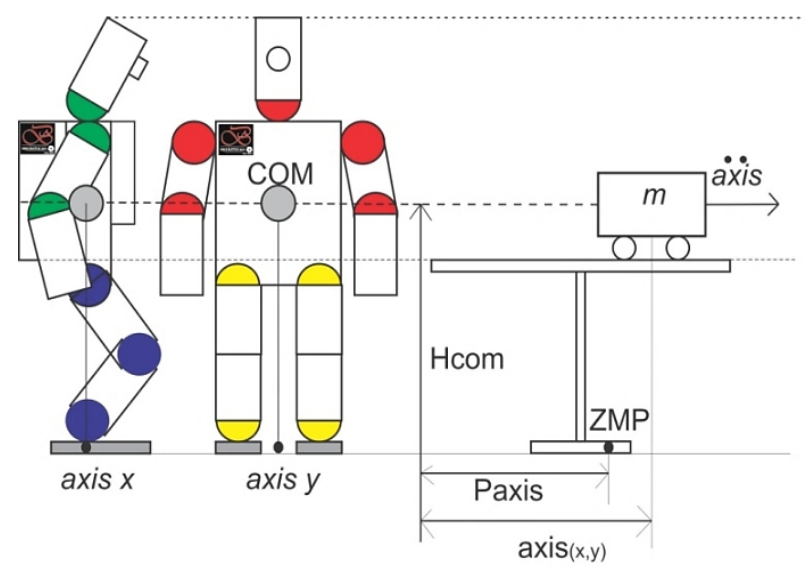

Gambar 2. Cart-Table Model (CTM) Robot Humanoid 


\section{TEKNIK, 40 (1), 2019, 4}

$$
\begin{aligned}
& P_{x}=x-\left(\frac{H_{C O M}}{g} \times x\right) \\
& P_{y}=y-\left(\frac{H_{C O M}^{g}}{g} \times y\right)
\end{aligned}
$$

Sesuai formulasi CTM (Kajita, et al., 2003) dan (Peng, Shui, Li, \& Ma, 2010), persamaan (1) dan (2) merumuskan hubungan antara nilai pergeseran ZMP pada sumbu $x$ dan y terhadap ayunan CoM. Besarnya Px dan Py, yang merupakan momen pada sumbu X dan Y, ditentukan oleh pergeseran CoM pada robot humanoid. Pemodelan dianalogikan sebagai Cart dengan massa tertentu. Sedangkan kaki meja dianalogikan sebagai titik tumpu robot dimana ZMP bergeser. Sistem pergerakan robot humanoid adalah sistem yang unpredictable, sehingga untuk dapat berjalan dengan seimbang maka dibutuhkan sensor keseimbangan yang diaplikasikan ke bentuk pemodelan tersebut. Dalam hal ini, gyro dan akselerometer berfungsi sebagai kompensator dari goncangan atau slip pada pergerakan robot.

Nilai kompensasi yang telah dinormalisasi dengan kebutuhan sistem kemudian digunakan sebagai pengurang atau penambah goal position (pada joint offset) servo-servo yang berkaitan dengan keseimbangan pada sumbu X dan Y. Perhatikan Gambar 2, sebagai contoh pada sumbu Y (ayunan kanan-kiri), servo yang menjaga kestabilan robot adalah servo kaki yang berwarna kuning serta servo tangan yang berwarna merah yang terletak pada pangkal tangan. Sedangkan pada sumbu X (arah depan-belakang), servo yang menjaga keseimbangan adalah servo kaki berwarna biru serta servo tangan berwarna hijau yang terletak pada pangkal tangan. Dengan memberikan nilai kompensasi pada joint offset servo maka sistem keseimbangan robot tetap dapat dipertahankan meskipun terdapat selip atau goncangan.

\section{2. Sistem Penglihatan untuk Pendeteksian Objek}

Sistem sensor visual berupa modul kamera C3088 dengan board CMUCAM digunakan untuk pengenalan dan tracking objek, yakni bola dan gawang. Object detection and tracking merupakan proses yang bertujuan untuk mengenali dan mengisolasi suatu objek tertentu untuk diketahui lokasi keberadaannya (Ismael \& Hedley, 2016). Proses detection berfokus pada pencarian keberadaan objek yang belum terdeteksi oleh kamera, sedangkan proses tracking bertujuan untuk mengikuti perpindahan objek agar selalu bisa terdeteksi dan tidak terlepas dari jangkauan kamera (Stephon \& Khorbotly, 2012). Objek yang dimaksud pada penelitian ini adalah bola berwarna jingga berdiameter $6 \mathrm{~cm}$ serta gawang berwarna kuning dan biru yang digunakan dalam pertandingan humanoid soccer kid size. Pendeteksian objek-objek tersebut harus dilakukan secara real time serta robust terhadap fluktuasi pencahayaan.
Kamera OV6620 pada modul kamera C3088 yang digunakan memiliki resolusi maksimal $352 \times 288$ piksel data RGB (Red, Green, and Blue) dengan kontroler berupa LPC2106. Citra berukuran $352 \times 288$ piksel hanya digunakan dalam proses detection, sedangkan dalam proses tracking dilakukan scaling setengah resolusi maksimal (176x144 piksel) guna mempercepat proses komputasi. Agar lebih mudah dalam mengenali warna dasar tanpa terpengaruh fluktuasi pencahayaan, maka ranah warna RGB ditransformasikan ke ranah warna HSV (Hue, Saturation, Value). Model ranah warna HSV diformulasikan oleh A.R. Smith pada tahun 1978 sebagai karakter warna intuitif yang merepresentasikan kelas warna, kejernihan, dan intensitas cahaya.

Keuntungan dari penggunaan ranah warna HSV pada pengolahan citra adalah adanya separasi antara warna dasar dengan luminansi sehingga untuk mengenali warna dasar hanya menggunakan nilai Hue dengan mengatur Saturation dan Value pada rentang tertentu (Farazi, Allgeuer, \& Behnke, 2018). Setelah diperoleh nilai-nilai piksel dalam ranah HSV, maka selanjutnya dilakukan segmentasi objek berdasarkan warna dasarnya dengan menggunakan nilai Hue. Proses segmentasi warna jingga, kuning, dan biru dilakukan dengan mempartisi garis warna Hue menjadi 3 bagian yaitu jingga, kuning, dan biru, sedangkan warna lain tidak akan ditandai/diabaikan. Interpretasi nilai Hue tersebut masih dalam bentuk derajat. Sedangkan jika direpresentasikan sebagai nilai warna 8-bit, maka Hue akan berkisar antara 0 sampai 180 , sedangkan nilai 180 - 255 tidak digunakan. Representasi nilai 8-bit Hue adalah nilai derajat dibagi 2. Dari informasi tersebut kemudian dibentuk matriks array yang terdiri 4 buah anggota, yaitu variabel warna $=\{$ warna 1 , warna 2 , warna 3 , warna 4$\}$, dengan penjelasan variabel :

1. Jingga $=$ bernilai $15-25$ sebagai warna 1

2. Kuning = bernilai $26-35$ sebagai warna 2

3. Biru $=$ bernilai $90-140$ sebagai warna 3

4. Di luar batasan tersebut tidak digunakan, yaitu sebagai warna 4

Visualisasi proses pengolahan citra sampai pada tahap segmentasi dan ekstraksi ciri ditampilkan pada Gambar 3. Dari proses tersebut dihasilkan nilai-nilai batas bounding box objek yang meliputi $\mathrm{X}_{\min }, \mathrm{X}_{\max }$, $\mathrm{Y}_{\min }$, dan $\mathrm{Y}_{\max }$ pada tiap-tiap objek (warna 1, warna 2, warna 3, atau warna 4). Selanjutnya nilai-nlai tersebut diolah dengan persamaan (3) sampai dengan persamaan (10) untuk mengetahui spesifikasi objek antara lain titik tengah bounding box $(\mathrm{x}, \mathrm{y})$, luasan bounding box, serta lokasi centroid $(\mathrm{x}, \mathrm{y})$ yang kemudian digunakan untuk pengembangan algortima detection dan tracking pada robot humanoid pemain bola. 


\section{TEKNIK, 40 (1), 2019, 5}
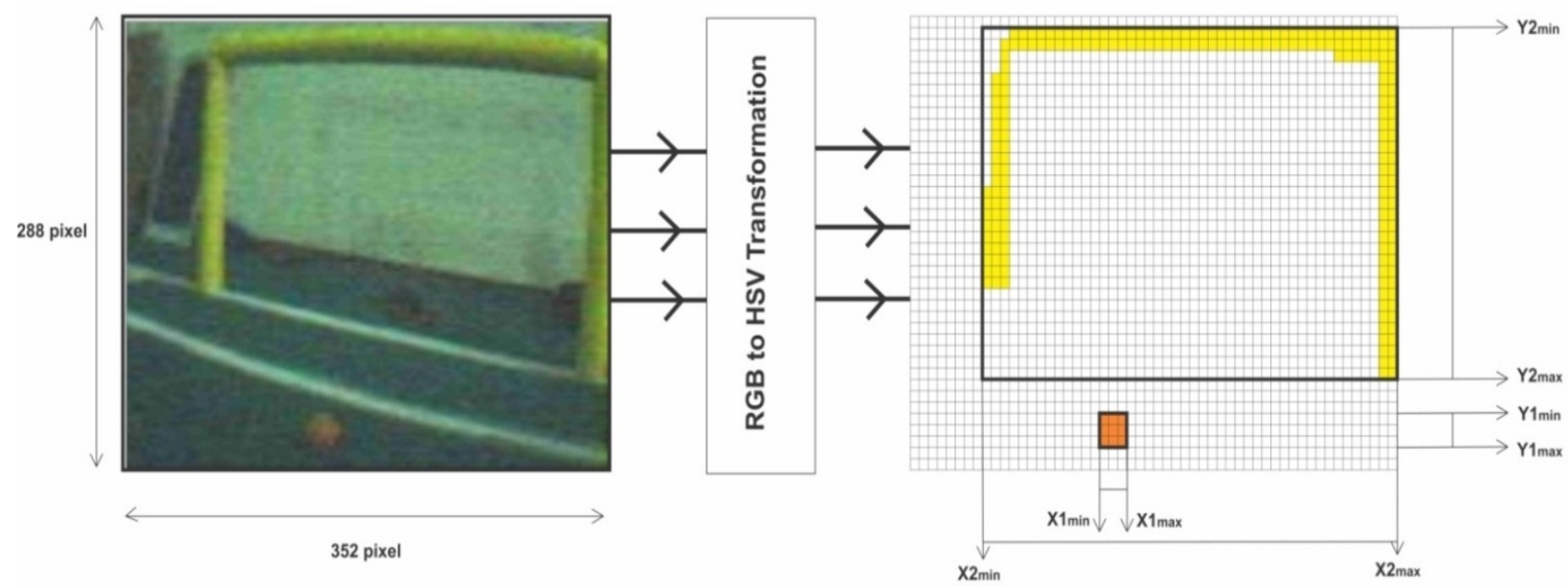

Gambar 3. Proses Segmentasi Citra Berbasis Warna pada Robot untuk Detection and Tracking pada Bola dan Gawang

$$
\begin{gathered}
\Delta_{x}=x_{\max }-x_{\min } \\
\Delta_{y}=y_{\max }-y_{\min } \\
A_{\text {bounding }}=\Delta_{x} \times \Delta_{y} \\
x_{\text {mid }}=x_{\min }+\frac{\Delta_{x}}{2} \\
x_{\text {mid }}=x_{\min }+\frac{\Delta_{x}}{2} \\
y_{\text {mid }}=y_{\min }+\frac{\Delta_{y}}{2} \\
C_{x}=\frac{2_{i=0}^{n} x_{i} \times n}{A_{\text {bounding }}} \\
C_{y}=\frac{2_{i=0}^{n} y_{1} \times n}{A_{\text {bounding }}}
\end{gathered}
$$

Pada pengolahan citra, bounding box merupakan wilayah yang meliputi sebuah objek tertentu dengan luasan wilayah yang disebut sebagai bounding area. Sedangkan centroid didefinisikan sebagai center of mass dari objek tersebut. Istilah centroid tersebut dicetuskan pertama kali oleh Archimedes dan banyak diadopsi dalam bidang matematika dan fisika untuk menentukan pusat massa, mean average atau center of symmetry dari sebuah bidang (Apostol \& Mnatsakanian, 2000). Pada objek yang simetris, centroid terletak tepat di titik tengah bounding box.

\section{3. Algoritma Permainan Robot Pemain Bola}

Blok diagram sistem secara keseluruhan dijabarkan pada Gambar 4. Jika dikelompokkan, sistem kontrol pada robot humanoid yang dikembangkan terdiri dari 3 kelompok sistem kontrol, yaitu,
1. Visual and Intelligence Control: sistem penglihatan dan kecerdasan (algoritma permainan) robot yang dikendalikan melalui board CMUCam.

2. Information and Direction Control: sistem pengontrol pusat informasi untuk robot (informasi arah gawang dan informasi state dari controller) yang dikontrol oleh custom board ATMega 8.

3. Motion and Balance Control: sistem kontrol untuk locomotion dan keseimbangan robot yang dikontrol oleh board CM-700.

Flowchart algoritma permainan robot pemain bola dijelaskan pada Gambar 5. Secara sekuensial, robot akan mengeksekusi sub-bagian gerakan sesuai dengan tahapan bermain bola, yakni mencari keberadaan bola, mendekat ke lokasi bola berada, kemudian memposisikan diri untuk kemudian mencari gawang dan menendang bola ke arah gawang. Sistem permainan bola yang dikembangkan pada penelitian ini belum melibatkan koordinasi antar robot, sehingga hanya berfokus pada permainan individual.

\section{Hasil dan Pembahasan}

Pengujian robot humanoid pemain bola dilakukan dalam beberapa tahap, meliputi:

1. Pengujian sistem gerak (gait generation)

2. Pengujian sistem keseimbangan robot

3. Pengujian ball tracking

4. Pengujian permainan bola secara real-time

Selain itu, proses kalibrasi dilakukan sebelum robot diuji coba untuk melakukan permainan sepakbola, kalibrasi meliputi kalibrasi pencahayaan lingkungan (pengaturan fokus kamera, gain, dan white balance kamera), serta pengaturan arah kompas terhadap gawang sendiri dan gawang lawan. 
TEKNIK, 40 (1), 2019, 6

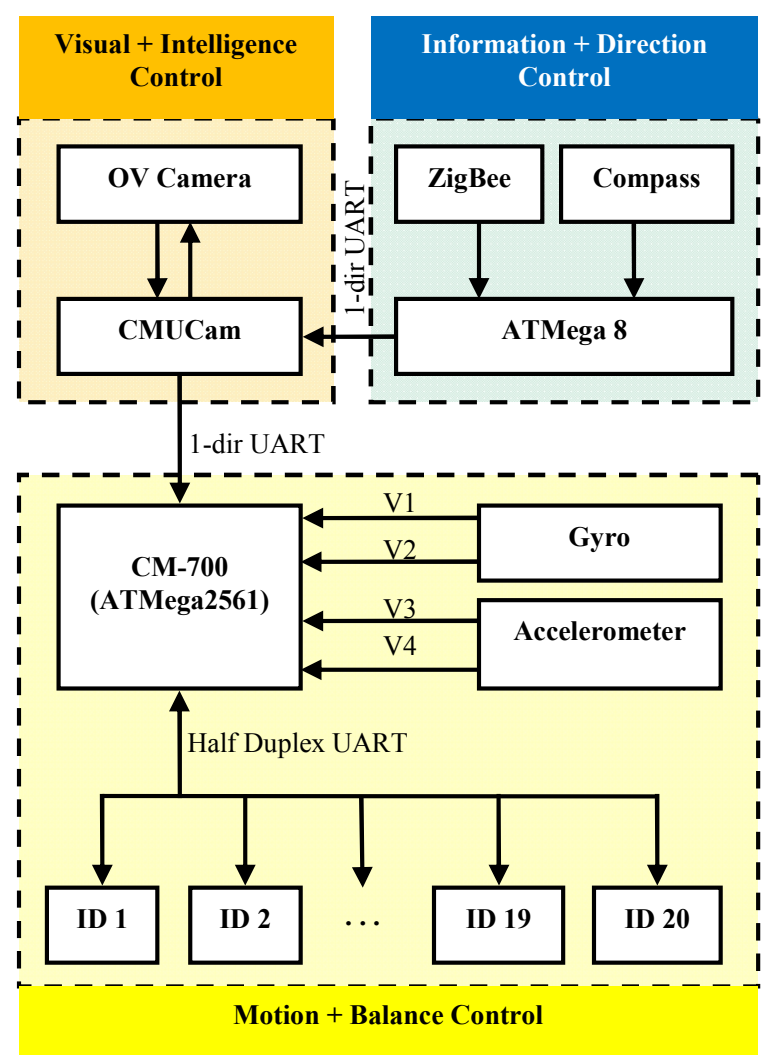

Gambar 4. Diagram Alir Sistem pada Robot Humanoid Pemain Bola yang Dikembangkan

\section{1. Pengujian Sistem Gerak (Gait Generation)}

Pembuatan gerakan robot (gait generation) memanfaatkan metode angle trackback dari pose robot yang dibuat secara manual. Proses Tuning pose robot dilakukan dengan cara menggerakkan tubuh robot dengan mematikan torsi servo untuk membentuk postur dan kemudian menyimpan nilai-nilai sudut masingmasing sendi pada Look Up Table (LUT).

Pose-pose robot yang disusun merupakan bagian dari sebuah step pergerakan yang disimpan dalam array penerjemah bagian gerakan robot. Oleh kontroler, bagian-bagian gerakan tersebut dipanggil sesuai urutan dalam sebuah gerakan robot, dan disusun untuk membentuk gerakan utuh pada robot, misal untuk jalan ke depan, mundur, serong, dan sebagainya. Penggunaan LUT cukup efektif diterapkan pada sistem dengan kecepatan prosesor yang tidak terlalu tinggi dimana tidak diperlukan perhitungan inverse kinematics and dynamics secara terus menerus. Nilai-nilai pose yang disusun dalam LUT tersebut kemudian dikelompokkan menjadi gugus-gugus jenis gerakan yang disambungkan melalui gerakan-gerakan transisi.

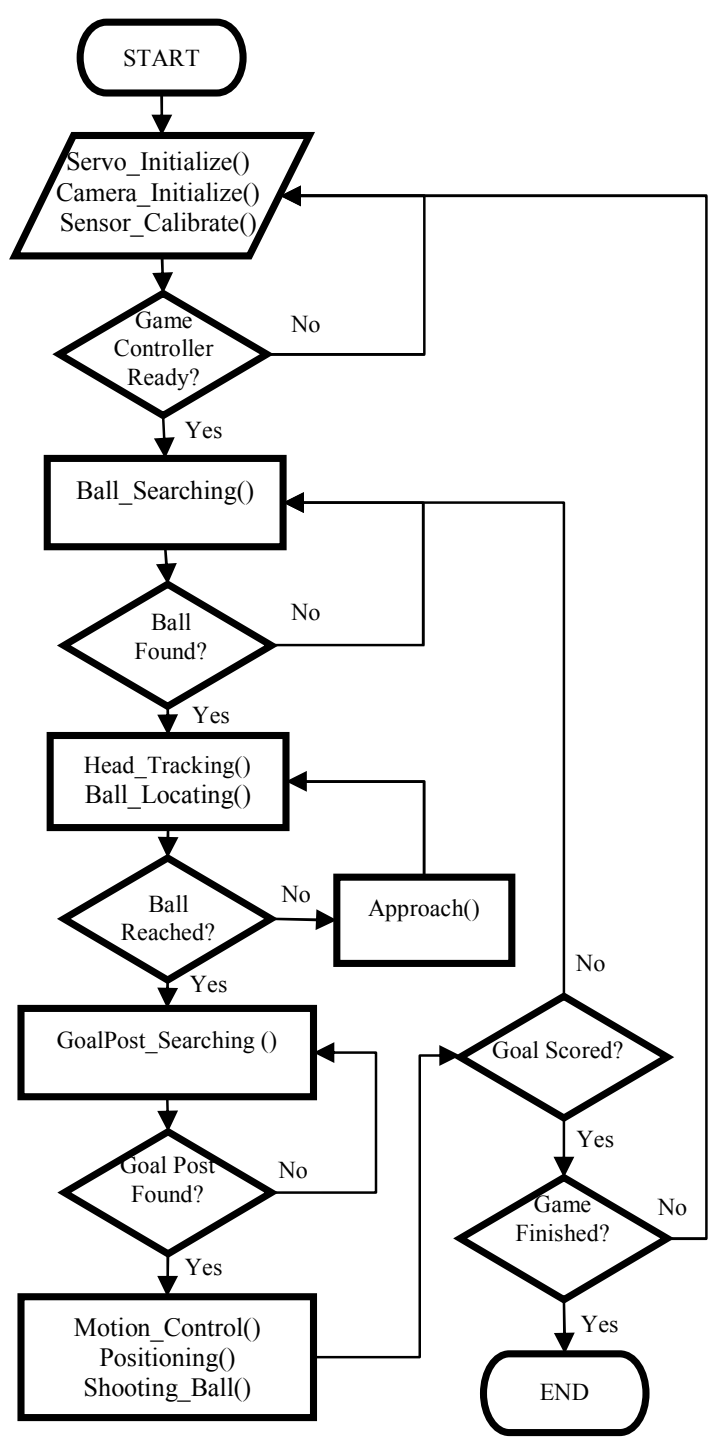

Gambar 5. Rancangan Diagram Alir untuk Algoritma Permainan pada Robot Humanoid Pemain Bola 


\section{TEKNIK, 40 (1), 2019, 7}
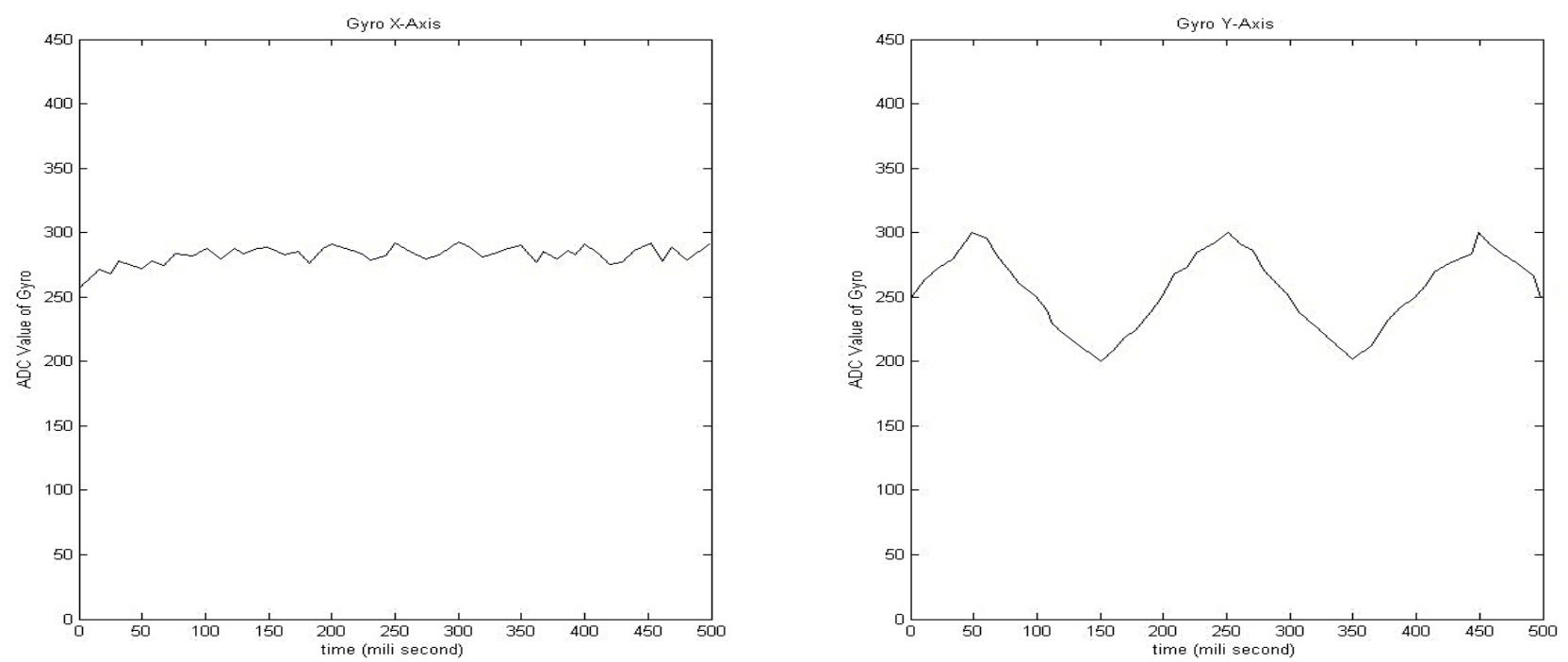

Gambar 6. Pembacaan Nilai ADC Sumbu X dan Y pada Gyro Ketika Robot Berjalan

\section{2. Pengujian Sistem Keseimbangan Robot}

Pada robot pemain bola, sistem keseimbangan berbasis inersia sebenarnya hanya dibutuhkan ketika terjadi ketidakseimbangan yang diakibatkan slip, sandungan, atau tabrakan, sehingga pada kondisi normal locomotion robot dapat dianggap sebagai static walking. Pada kondisi jalan yang ideal (tanpa gangguan) maka kompensator keseimbangan tidak terlalu berperan signifikan dalam menyeimbangkan tubuh robot. Dengan berpedoman pada CTM, maka gyro dapat diterapkan pada joint offset robot setiap kali robot mengalami transisi gerakan. Nilai ADC gyro direkam dalam bentuk unsigned integer 9-bit, yaitu pada rentang 0 sampai dengan 511. Pembacaan nilai sensor gyro pada sumbu X dan $\mathrm{Y}$ saat robot berjalan stabil ditampilkan pada Gambar 6.

Nilai ADC akselerometer direkam dalam bentuk bilangan unsigned integer 10-bit. Pada pengujian yang dilakukan, data akselerometer diambil dengan sampling time 10 ms. Ada 4 jenis kondisi postur tubuh robot yang diuji antara lain: berdiri standby, berjalan dengan stabil, jatuh ke depan, dan jatuh ke belakang. Pada masingmasing kondisi postur tersebut data akselerometer direkam selama 20 detik. Rekaman data akselerometer dalam 4 jenis postur tersebut ditampilkan dalam bentuk box-and-whisker chart pada Gambar 7 (kondisi berdiri tegak dan berjalan stabil) dan Gambar 8 (jatuh ke depan dan ke belakang). Pada kondisi berdiri tegak, nilai median data sensor berada pada 555 dengan rentang 550 sampai 560, sedangkan ketika berjalan stabil, nilai median sensor bernilai 585 dengan rentang nilai yang cukup lebar dari 546 hingga 598. Nilai median dan range pada jatuh depan dan belakang digunakan sebagai parameter fall detection.

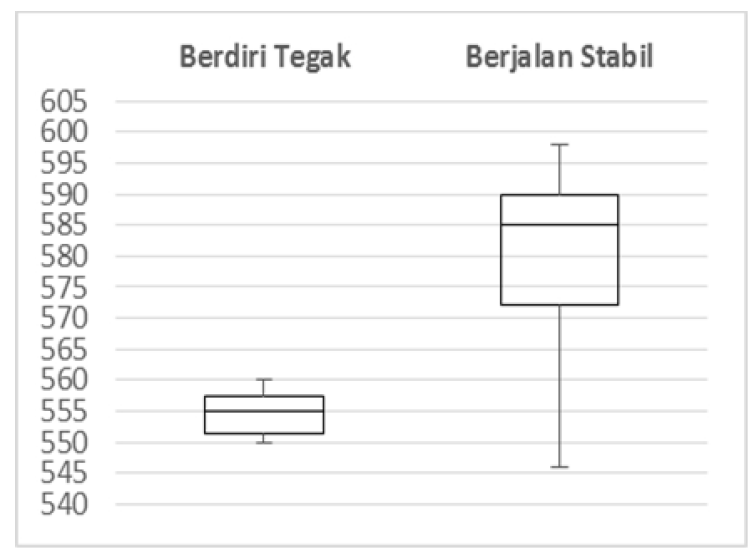

Gambar 7. Hasil Pengujian Nilai Sensor Gyro pada Kondisi Robot Berdiri Tegak dan Berjalan Stabil

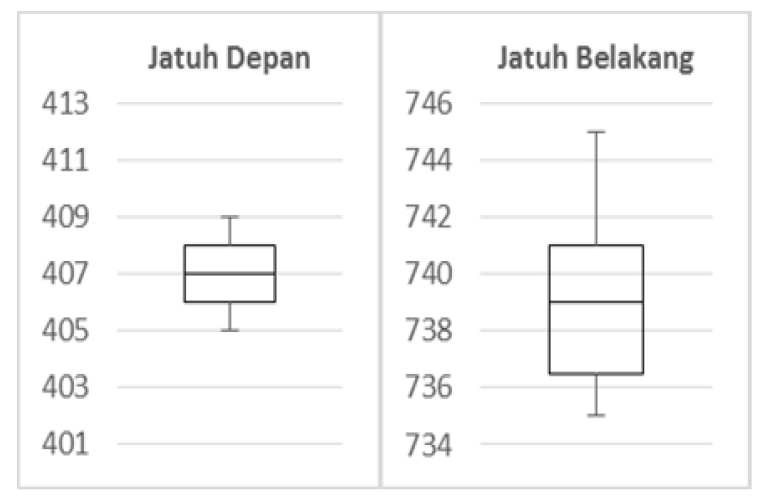

Gambar 8. Hasil Pengujian Nilai Sensor Gyro pada Kondisi Robot Jatuh ke Depan dan Jatuh ke Belakang 


\section{TEKNIK, 40 (1), 2019, 8}
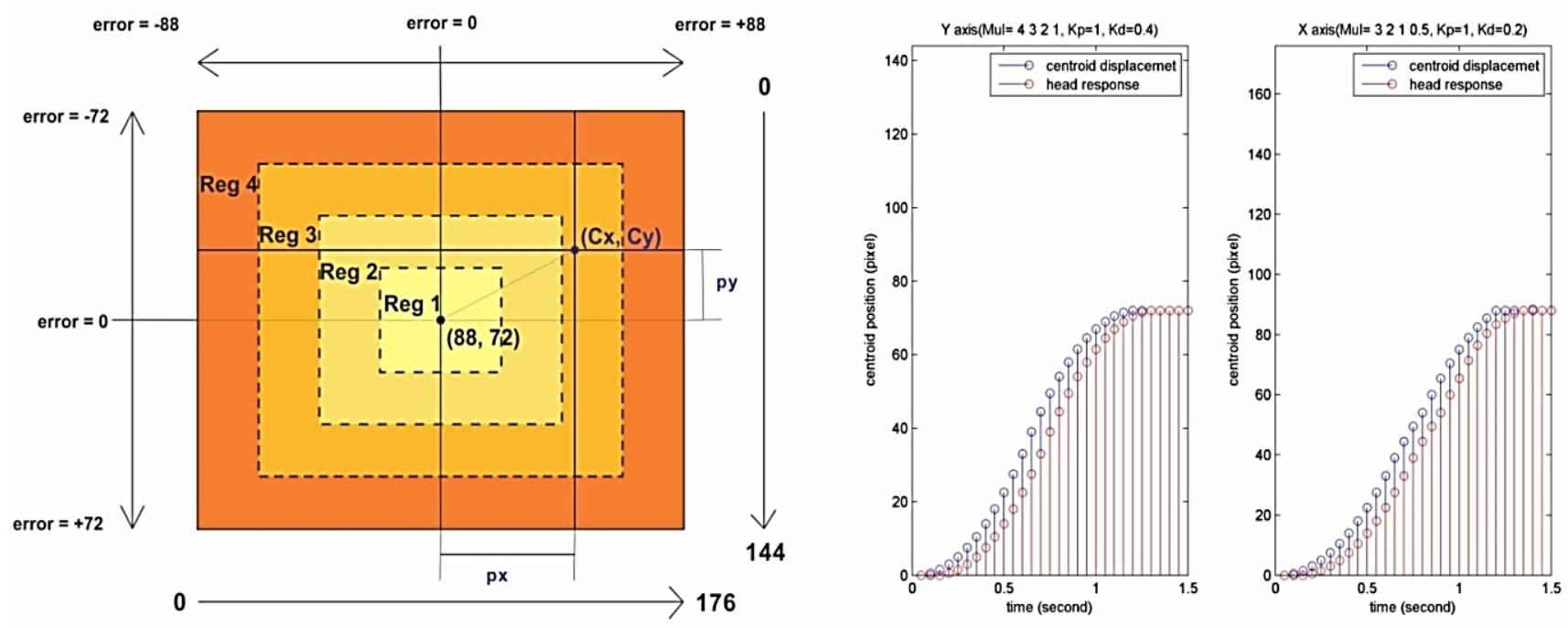

Gambar 9. Pembagian Wilayah Tracking (Kiri) dan Hasil Pengujian Tuning Parameter Pengali, Kp, dan Kd Optimal pada Saat Mode Tracking (Kanan)

\section{3. Pengujian Ball Tracking dengan mode Active Head}

Pengujian bal tracking dengan mode active head dilakukan menggunakan objek bola tenis warna jingga berdiameter $6 \mathrm{~cm}$ dengan background lapangan berwarna hijau. Lensa standar yang digunakan CMUCam memiliki focal point $4.9 \mathrm{~mm}$ dengan jangkauan sudut maksimal $25^{\circ}$, yakni sudut jangkauan pada sumbu $X$ dan sumbu $Y$ bernilai sekitar $20.9^{\circ}$ dan $15.4^{\circ}$ (Rowe, Goode, Goel, \& Nourbakhsh, 2007). Frame citra dibagi menjadi 4 wilayah dengan batasan pada sumbu X tersekat tiap 44 piksel dan sumbu Y tersekat tiap 36 piksel (ditunjukkan dengan perbedaan warna pada frame Gambar 9 bagian kiri).

Pada pengujian, posisi kepala lurus menghadap ke depan dengan kondisi awal tanpa objek yang akan dideteksi. Kemudian bola sebagai objek yang akan diikuti dimunculkan sehingga terdeteksi oleh kamera pertama kali pada posisi $(0,0)$, yaitu pada ujung kiri atas kamera. Dari stimulus tersebut maka kepala (yang terdiri dari servo pan and tilt) akan melakukan pergerakan tracking agar centroid warna bola berada pada titik tengah kamera. Letak centroid target bola dan titik tengah kamera relatif terhadap centroid kemudian dikirimkan ke PC melalui serial UART tiap 0.05 detik. Hasil pengujian ball tracking dengan berbagai nilai pengali pada masing-masing wilayah, Kp, dan Kd pada sumbu X dan Y ditampilkan pada Tabel 1 dan 2. Respon sistem pada tuning optimal ditampilkan Gambar 9 (bagian kanan).
Tabel 1. Pengujian Mode Head-Tracking pada Sumbu $\mathrm{X}$ dengan Tuning Nilai Pengali Wilayah pada berbagai Konstanta Proportional dan Derivative

\begin{tabular}{rrrrrrrl}
\hline \multirow{2}{*}{ No } & \multicolumn{3}{c}{ Pengali Wilayah } & \multicolumn{2}{c}{ Kp } & Kd & \multicolumn{1}{c}{ Kondisi } \\
\cline { 2 - 5 } & $\mathbf{4}$ & $\mathbf{3}$ & $\mathbf{2}$ & $\mathbf{1}$ & & & \\
\hline 1 & 7 & 5 & 3 & 2 & 3 & 3 & Terjadi Osilasi \\
2 & 6 & 4 & 3 & 2 & 3 & 2 & Terjadi Osilasi \\
3 & 5 & 4 & 3 & 2 & 2 & 1 & Terjadi Osilasi \\
4 & 5 & 4 & 3 & 1 & 2 & 0.6 & Terjadi Osilasi \\
5 & 4 & 3 & 2 & 1 & 2 & 0.5 & Terjadi Osilasi \\
6 & 4 & 3 & 2 & 1 & 1 & 0.4 & Respon Tepat \\
7 & 4 & 3 & 2 & 1 & 1 & 0.3 & Respon Lambat \\
8 & 4 & 3 & 2 & 1 & 1 & 0.2 & Respon Lambat \\
9 & 4 & 3 & 2 & 1 & 1 & 0.1 & Respon Lambat \\
10 & 4 & 3 & 2 & 1 & 1 & 0.05 & Respon Lambat \\
\hline
\end{tabular}

Tabel 2. Pengujian Mode Head-Tracking pada Sumbu Y dengan Tuning Nilai Pengali Wilayah pada berbagai Konstanta Proportional dan Derivative

\begin{tabular}{|c|c|c|c|c|c|c|c|}
\hline \multirow{2}{*}{ No } & \multicolumn{4}{|c|}{ Pengali Wilayah } & \multirow{2}{*}{ Kp } & \multirow{2}{*}{ Kd } & \multirow{2}{*}{ Kondisi } \\
\hline & 4 & 3 & 2 & 1 & & & \\
\hline 1 & 5 & 4 & 3 & 2 & 2 & 3 & Terjadi Osilasi \\
\hline 2 & 4 & 3 & 2 & 1 & 2 & 2 & Terjadi Osilasi \\
\hline 3 & 4 & 3.5 & 3 & 2.5 & 2 & 1 & Terjadi Osilasi \\
\hline 4 & 4 & 3 & 2.5 & 1.5 & 2 & 0.6 & Terjadi Osilasi \\
\hline 5 & 4 & 3 & 2 & 1 & 2 & 0.4 & Terjadi Osilasi \\
\hline 6 & 3 & 2 & 1 & 0.5 & 1 & 0.2 & Respon Tepat \\
\hline 7 & 3 & 2 & 1 & 0.5 & 1 & 0.1 & Respon Lambat \\
\hline 8 & 3 & 2 & 1 & 0.5 & 1 & 0.05 & Respon Lambat \\
\hline
\end{tabular}




\section{TEKNIK, 40 (1), 2019, 9}

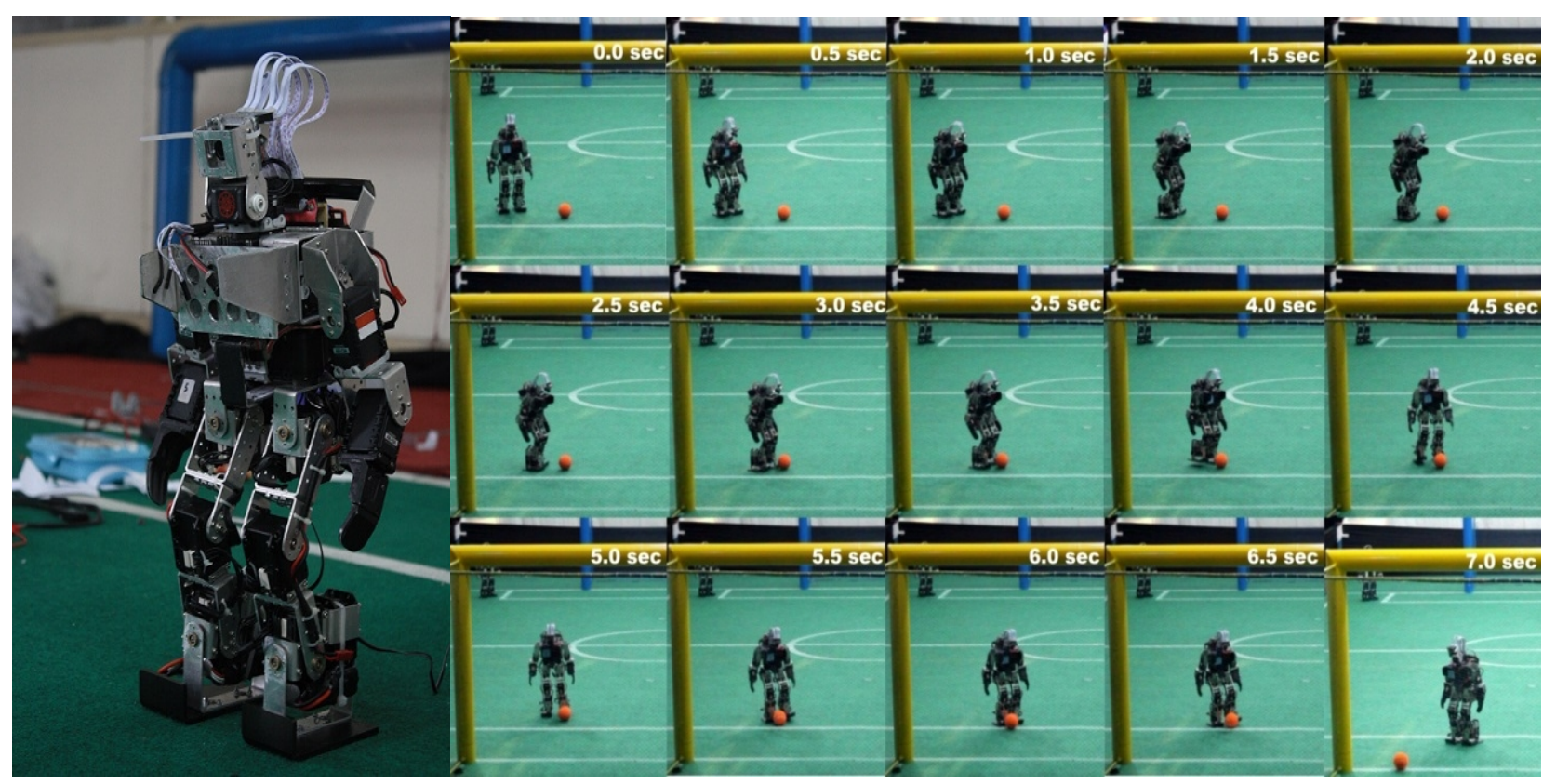

Gambar 10. Robot Humanoid pada Mode Standby (Kiri) dan pada Saat Bermain Bola secara Otonom (Kanan)

\section{4. Pengujian Robot Humanoid Bermain Bola secara Real-Time}

Penilaian performa robot kemudian dilakukan dengan menguji kecepatan jalan, kekuatan tendangan, serta running test permainan individu robot dalam lapangan. Hasil pengujian kecepatan jalan dilakukan dengan menguji kecepatan robot menuju bola berwarna jingga dengan posisi awal robot diletakkan pada titik tengah lapangan dan posisi bola berada tepat di mulut gawang. Hasil pengujian kecepatan jalan ditunjukkan pada Tabel 3. Berdasarkan 5 kali pengujian, diperoleh kecepatan jalan rerata robot adalah $16.36 \mathrm{~cm} /$ detik.

Pengujian kekuatan dan kecepatan tendangan dilakukan untuk menguji kekuatan dan kecepatan tendangan robot terhadap bola tenis standar berdiameter $6 \mathrm{~cm}$. Cara pengujiannya adalah dengan menempatkan bola dan robot pada titik penalti sendiri dengan arah tendangan menuju ke gawang lawan. Waktu tempuh diukur tepat sebelum bola bergerak sampai ketika bola benar-benar berhenti. Hasil pengujian kekuatan tendangan ditampilkan pada Tabel 4. Berdasarkan 5 kali pengujian jarak rerata kekuatan tendangan adalah 507.34 $\mathrm{cm} /$ detik dengan kecepatan rerata tendangan 45.3 $\mathrm{cm} /$ detik. Pengujian permainan individu ditampilkan pada Gambar 10. Dengan menggunakan algoritma dan skenario sesuai dengan yang dijabarkan pada Gambar 4 dan Gambar 5, pada bola dengan jarak dekat (tepat di luar kotak penjaga gawang) robot humanoid yang dikembangkan mampu mencetak gol dalam waktu \pm 7 detik.
Tabel 3. Hasil Pengujian Kecepatan Jalan Robot Humanoid

\begin{tabular}{ccr}
\hline $\begin{array}{c}\text { Percobaan } \\
\text { Ke- }\end{array}$ & $\begin{array}{c}\text { Jarak Robot - } \\
\text { Bola (cm) }\end{array}$ & $\begin{array}{c}\text { Waktu Tempuh } \\
\text { (detik) }\end{array}$ \\
\hline 1 & 300 & 18.4 \\
2 & 300 & 17.9 \\
3 & 300 & 18.5 \\
4 & 300 & 18 \\
5 & 300 & 18.9 \\
\hline Rerata & 300 & 18.34 \\
\hline Kecepatan Rerata (cm/detik) & $\mathbf{1 6 . 3 6}$ \\
\hline
\end{tabular}

Tabel 4. Hasil Pengujian Kekuatan Tendangan berdasarkan Jarak dan Kecepatan Bola

\begin{tabular}{ccr}
\hline $\begin{array}{c}\text { Percobaan } \\
\text { Ke- }\end{array}$ & $\begin{array}{c}\text { Jarak Bola Awal } \\
\text { - Akhir (cm) }\end{array}$ & $\begin{array}{c}\text { Waktu Tempuh } \\
\text { (detik) }\end{array}$ \\
\hline 1 & 514.5 & 11.4 \\
2 & 520.4 & 12 \\
3 & 497.7 & 11.1 \\
4 & 513.4 & 10.9 \\
5 & 490.7 & 10.6 \\
\hline Rerata & 507.34 & 11.2 \\
\hline Kecepatan Rerata (cm/detik) & $\mathbf{4 5 . 3 0}$ \\
\hline
\end{tabular}

\section{Kesimpulan}

Robot humanoid pemain bola otonom yang dikembangkan mampu berjalan dengan kecepatan maksimal $20 \mathrm{~cm} /$ detik, serta mampu bermain bola secara autonomous dengan kecepatan jalan dalam kondisi ball tracking rata-rata $16.36 \mathrm{~cm} /$ detik. Robot mampu berdiri 


\section{TEKNIK, 40 (1), 2019, 10}

kembali saat terjatuh (fall-recovery) dengan baik serta mampu berjalan dengan seimbang untuk bermain bola. Kekuatan tendangan sudah cukup kuat dengan jarak tendang rata-rata mencapai $\pm 500 \mathrm{~cm}$. Dalam sebuah simulasi pertandingan, robot mampu mencetak gol ke gawang lawan dalam waktu yang relatif cepat. Pada posisi bola tepat di luar kotak penalti, robot mampu mencetak gol dalam waktu \pm 7 detik.

\section{Ucapan Terima Kasih}

Terima kasih disampaikan kepada UNDIP Robotics Development Center (URDC) - Universitas Diponegoro dan Gadjah Mada Robotics Team (GMRT) - Universitas Gadjah Mada, yang telah mendukung penelitian ini.

\section{Daftar Pustaka}

Antonello, R., \& Oboe, R. (2011). MEMS gyroscopes for consumers and industrial applications. In Microsensors. IntechOpen.

Apostol, T. M., \& Mnatsakanian, M. A. (2000). Finding centroids the easy way. Math Horizons, 8, 7-12.

Bliley, K. E., Schwab, D. J., Holmes, D. R., Kane, P. H., Levine, J. A., Daniel, E. S., \& Gilbert, B. K. (2006). Design of a compact system using a MEMS accelerometer to measure body posture and ambulation. 19th IEEE Symposium on Computer-Based Medical Systems (CBMS'06), 335-340.

Burkhard, H.-D., Duhaut, D., Fujita, M., Lima, P., Murphy, R., \& Rojas, R. (2002). The road to RoboCup 2050. IEEE Robotics \& Automation Magazine, 9, 31-38.

Farazi, H., Allgeuer, P., \& Behnke, S. (2018). A monocular vision system for playing soccer in low color information environments. arXiv preprint arXiv: 1809.11078.

Gerndt, R., Seifert, D., Baltes, J. H., Sadeghnejad, S., \& Behnke, S. (2015). Humanoid robots in soccer:
Robots versus humans in RoboCup 2050. IEEE Robotics \& Automation Magazine, 22, 147-154.

Ismael, O. Y., \& Hedley, J. (2016). Development of an Omnidirectional Mobile Robot Using Embedded Color Vision System for Ball Following. American Scientific Research Journal for Engineering, Technology, and Sciences (ASRJETS), 22, 231-242.

Kajita, S., Kanehiro, F., Kaneko, K., Fujiwara, K., Harada, K., Yokoi, K., \& Hirukawa, H. (2003). Biped walking pattern generation by using preview control of zero-moment point. 2003 IEEE International Conference on Robotics and Automation (Cat. No. 03CH37422), 2, 16201626.

Kim, K.-I., Son, Y. I., \& Kim, P. B. (2004). Construction of small humanoids with a new joint actuator module. IEEE International Conference on Robotics and Automation, 2004. Proceedings. ICRA'04. 2004, 5, 4510-4514.

Mobalegh, H. (2012). Development of an autonomous humanoid robot team. Ph.D. dissertation.

Peng, S., Shui, H., Li, G., \& Ma, H. (2010). Walking gait planning of humanoid soccer robot based on the desired ZMP trajectories. 2010 The 2nd International Conference on Industrial Mechatronics and Automation, 2, 127-131.

Rowe, A., Goode, A., Goel, D., \& Nourbakhsh, I. (2007). CMUcam3: An open programmable embedded vision sensor. International conferences on intelligent robots and systems.

Smith, A. R. (1978). Color gamut transform pairs. ACM Siggraph Computer Graphics, 12, 12-19.

Stephon, A. C., \& Khorbotly, S. (2012). A camera-based target tracking system for football playing robots. Proceedings of the 2012 44th Southeastern Symposium on System Theory (SSST), 164-167.

Thai, C. N. (2017). ROBOTIS_Robot Systems. Exploring Robotics with ROBOTIS Systems, 5-21. Springer. 